\title{
Semangat Patriotik Masyarakat Cina: Analisis Teori Relevans (Patriotic Sentiment of Chinese Community: A Relevance Theory Analysis)
}

\author{
MONICA LIAW KAH PEI* \& MARY FATIMAH SUBET \\ Fakulti Bahasa dan Komunikasi, Universiti Malaysia Sarawak, 94300 Kota Samarahan, Sarawak, \\ Malaysia
}

*Corresponding author: monicaliaw.mlp@gmail.com

\begin{abstract}
ABSTRAK
Masyarakat Cina terkenal dangan sikap patriotik mereka. Namun semangat ini tidak ditunjukkan secara langsung. Makalah ini bertujuan untuk mengesan gambaran budaya masyarakat Cina yang boleh didapati dalam sajak Melayu. Teori yang diaplikasi ialah Teori Relevans (TR) yang dipelopori oleh Sperber dan Wilson (1986). Kajian ini ialah kajian kualitatif. Tiga sajak hasil penulisan Lim Swee Tin (LST), seorang penggiat sastera yang tersohor dianalisis. Baris-baris yang memaparkan semangat patriotik telah dikenal pasti daripada data korpus dan seterusnya dianalisis menggunakan TR. Dapatan kajian menunjukkan semangat patriotik yang terkenal dalam kalangan masyarakat Cina telah dikesan dalam sajak yang dihasilkan oleh LST ini. Kajian juga mendapati ada maklumat yang terselindung di sebalik baris-baris data yang dianalisis, di samping turut mengesan terdapatnya kaitan nilai serta budaya dalam masyarakat Cina. Akhirnya, kupasan data dengan aplikasi TR penting kerana hasil interpretasi yang diperoleh adalah lebih teoretikal, bersifat ilmiah dan sah dari segi kesahihannya. Hasil analisis bukan sahaja tidak akan dipertikaikan bahkan juga akan dapat menambahkan fakta, pemahaman dan pengetahuan yang sedia ada dalam kalangan masyarakat Cina terutamanya dari segi budaya masyarakat Cina.
\end{abstract}

Kata Kunci: Budaya Masyarakat Cina, Kesusasteraan Melayu, Lim Swee Tin, Sperber \& Wilson, Teori Relevans.

\begin{abstract}
In the Chinese community, patriotism had been a strong sentiment, but this sentiment had not been shown openly among the Chinese. Thus, this article aimed to identify the patrotic sentiments of the Chinese community in the Malay poems by applying relevance theory pioneered by Sperber and Wilson (1986). This is a qualitative study. Three poems written by Lim Swee Tin (LST), a famous Malaysian poet were analysed. Poetic lines in the poems that manifested the patriotic sentiments were identified from corpora and they were further analysed with relevance theory. Findings of the study showed that data consisting the patriotic sentiments practised by the Chinese were identified in LST's poems. The results also showed that there were implicit meanings behind the data analysed and the implied meanings and messages had been found to be in relevance with the values and cultures practised in the Chinese community. Not only that, the study also highlighted the importance of relevance theory in analysing the data as results obtained were more theoretical, academic and of high validity. Thus, the results obtained were not only undisputed, but it also an add-on to the existing facts, understanding and knowledge to the Chinese community particularly on the culture of Chinese community.
\end{abstract}

Keywords: Chinese culture, Lim Swee Tin, Malay Literature, Relevance Theory, Sperber \& Wilson.

Copyright: This is an open access article distributed under the terms of the CC-BY-NC-SA (Creative Commons AttributionNonCommercial-ShareAlike 4.0 International License) which permits unrestricted use, distribution, and reproduction in any medium, for non-commercial purposes, provided the original work of the author(s) is properly cited.

\section{PENGENALAN}

Kesusasteraan merujuk kepada hasil seni yang yang disampaikan melalui bahasa. Awang (1984) telah menyatakan sesebuah hasil sastera mengandungi unsur-unsur intelek, emosi, imaginasi dan teknik yang digunakan mahupun diserapkan oleh penulis. Oleh hal yang demikian, kesusasteraan merupakan suatu medium 
yang mampu membawa kepada perkembangan dan pengiktirafan status bahasa sebagai bahasa perantaraan dan bahasa perhubungan sesebuah negara (Salleh, 2015).

Dalam konteks Malaysia pula, karya sastera pada perkembangan awal bidang kesusasteraan telah dihasilkan dalam Bahasa Melayu sebelum berlakunya perkembangan penulisan dalam Bahasa Inggeris. Sajak pula mengalami perkembangan yang lebih akhir berbanding dengan genre yang lain iaitu pada tahun 1930-an yang turut dikenali sebagai Fecund period (Salleh, 2015). Dalam pada itu, Subet (2010) telah menjelaskan sajak sebagai ungkapan emosi dan pemikiran yang mampu menyentuh perasaan serta minda seseorang. Hal ini amat dipersetujui kerana bukan mudah untuk mengekspresikan perasaan, emosi dan pemikiran yang terpendam secara berterus-terang. Justeru, kaedah pengekspresian ini akan menjadi lebih mudah jika perasaan dan pemikiran tersebut diterjemahkan ke dalam baris-baris sajak yang indah. Selain itu, kaedah pengekspresian ini turut membuktikan bahasa sebagai saluran yang berkesan untuk meluahkan perasaan dan pemikiran manakala karya penulisan seperti hasil kesusasteraan merupakan produk akhir dan rekod kepada proses pengekspresian tersebut. Di samping itu, Shelley (dalam Pradopo, 1993) turut menjelaskan sajak sebagai rakaman kepada detik-detik memori yang indah, situasi keadaan yang sebenar serta pemikiran yang paling tulus dalam minda seseorang. Oleh hal yang demikian, ruang kajian yang luas telah dibentuk untuk menjalankan kajian bahasa dan budaya dalam sajak bukan sahaja dengan matlamat untuk memahami dan menyelami gambaran serta pandangan dunia masyarakat Melayu, malahan juga dengan tujuan untuk memahami diri sendiri, pemikiran manusia, masyarakat serta bangsa (Subet, 2010).

Bersangkutan dengan hasil kajian rintis yang telah diperoleh, kajian karya kesusasteraan terhadap hasil penulisan tokoh Melayu telah berlaku dengan pesat. Akan tetapi, tidak banyak kajian yang dijalankan terhadap tokoh Cina seperti LST yang menceburi bidang kesusasteraan Melayu dengan aktif. Di samping itu, kebanyakan kajian hasil kesusasteraan Melayu yang memberi tumpuan kepada kajian aspek kesusasteraan telah meninggalkan kelompangan kajian dalam bidang penyelidikan sastera Melayu kerana kurangnya penyelidikan yang mengkaji sajak dengan melihat kepada aspek budaya dalam kalangan masyarakat Melayu atau daripada masyarakat yang luar daripada Melayu. Di samping itu, kajian kesusasteraan lepas banyak tertumpu kepada aspek struktural dan hal ini turut mewujudkan kelompangan kajian kerana latar belakang seseorang penulis turut mempengaruhi penulisannya. Penulis akan memasukkan amalan budaya serta nilai murni yang pelbagai ke dalam sajak walaupun bahasa penulisan yang digunakan bukan Bahasa ibunda. Menyedari hakikat ini, makalah ini bertujuan untuk mengenal pasti makna tersirat dalam sajak serta membincangkan gambaran budaya Cina iaitu sentimen patriotik yang boleh didapati dalam sajak Melayu yang dihasilkan oleh penulis Cina melalui analisis TR secara kualitatif.

Sentimen patriotik, menurut Overseas Chinese Affairs Office (2001) merupakan nilai yang penting dalam masyarakat Cina untuk mengenal pasti kesetiaan dan ketaatan seseorang serta unsur nilai moralnya terhadap negara. Walaupun nilai ini menampakkan perubahan mengikut peredaran masa dan perbezaan di setiap negara, nilai ini memperlihatkan ciri-ciri seperti cinta akan tanah air, cinta kepada rakyat dan bangsa, saling menghormati dan berkongsi bahasa yang sama. Oleh hal yang demikian, nilai ini diibaratkan sebagai kuasa padu dalam masyarakat Cina yang mendorong seluruh bangsa untuk bersikap sayang, cinta dan taat setia serta sentiasa bersedia untuk maju ke hadapan demi negara. Bertitik tolak daripada penjelasan yang dikemukakan, kajian ini melakukan analisis TR terhadap sajak-sajak LST bagi mengesan gambaran sentimen patriotik dalam masyarakat Cina yang dapat dikaitkan secara tersirat dalam sajak beliau.

\section{KERANGKA TEORI, METODOLOGI DAN SUMBER DATA}

Analisis menggunakan TR daripada bidang pragmatik yang diasaskan oleh Sperber dan Wilson (1986). Menurut Sperber dan Wilson (1986), antara ciri yang penting dalam komunikasi verbal dan tidak verbal ialah pengekspresian dan pengiktirafan tujuan komunikasi tersebut diadakan. Hal ini adalah bercanggah dengan model komunikasi yang diperkenalkan oleh Grice (1975) kerana makna yang disampaikan dalam sesebuah komunikasi hanya merupakan satu bentuk input yang diperlu diinterpretasi dengan lebih lanjut lagi (Sperber \& Wilson, 1986). Dengan erti kata lain, input mempunyai makna tersirat yang memerlukan usaha pemprosesan yang lebih mendalam. Oleh itu, TR dalam bidang ilmu pragmatik haruslah diaplikasikan untuk menjelaskan dan menginterpretasikan makna yang tersirat dengan merujuk kepada maklumat konteks, kesan konteks dan juga usaha memproses. Ahmad dan Jalaluddin (2013) menyatakan bahawa konteks merupakan salah satu gagasan utama dalam TR dan daripada konteks pula, lahirlah kesan kognitif yang terhasil daripada maklumat yang diproses melalui sama ada salah satu sub-gagasan dalam TR iaitu penggabungan, penguatan atau pengguguran maklumat. 
Sperber dan Wilson (dalam Subet (2018) menyatakan bahawa apabila orang bercakap, makna sebenar yang dimaksudkan sering tidak disampaikan dengan sepenuhnya. Konteks memainkan peranan kerana konteks biasanya dapat disesuaikan dengan pelbagai interpretasi makna yang hendak disampaikan. Bagi mereka, pemahaman terhadap sesuatu ujaran ialah satu proses inferens yang mempunyai jangkauan makna yang luas. Bagaimanakah pemahaman ini dapat dicapai? TR yang mementingkan kewujudan konteks dalam interpretasi makna dapat menyelesaikan masalah makna yang taksa. Berasaskan pandangan ini, kajian ini berpendapat kaitan makna tersirat dengan nilai sentimen patriotik yang didapati dalam masyarakat Cina boleh dijadikan sebagai bukti untuk menyokong pandangan yang diujarkan dalam teori pragmatik yang terkenal ini. Menurut Subet (2010) dalam TR, konsep kod, inferens dan andaian akan digunakan secara meluas untuk langkah pembuktian. Daripada kod itu pula, proses membuat inferens akan dilakukan. Inferens diproses dalam minda. Proses membuat inferens perlu dilakukan untuk mencari andaian. Kemungkinan andaian yang tercetus akan difikirkan atau telah difikirkan. Menurut beliau lagi, andaian dalam TR mungkin terdiri daripada satu atau beberapa set andaian. Dalam TR, proses inferensi ini membolehkan satu rumusan terhadap andaian dibuat. Oleh itu, kemungkinan memperoleh pelbagai andaian itu sebenarnya telah terlebih dahulu melalui proses inferensi tadi. Proses membuat inferensi berlaku dengan pantas dalam minda manusia. Subet (2010) juga menyatakan matlamat utama proses ini ialah usaha mencari kerelevanan optimal tentang set andaian yang telah ditimbulkan dalam minda. Daripada set andaian tersebut, satu andaian sahaja akan berdiri kukuh. Dalam erti kata lain, set andaian tadi terdiri daripada beberapa andaian yang sama ada kuat atau lemah. Andaian yang lemah akan digugurkan, sementara andaian yang kukuh tadilah yang paling relevans dalam penginterpretasian makna sebenar yang hendak dinyatakan. Andaian yang benar-benar relevans ini akan diterima oleh minda untuk proses seterusnya.Untuk memahami andaian yang paling relevans tadi, kehadiran beberapa set maklumat pula diperlukan. Maklumat yang dimaksudkan ini menurut Jalaluddin (2013) pula merangkumi maklumat konteks, maklumat ensiklopedia, atau maklumat daripada memori jangka panjang atau pendek manusia. Dalam hal ini juga, pendengar turut dibenarkan mengemukakan andaian yang dibina secara ad-hoc. Ringkasnya, dalam TR, konsep ad-hoc ialah konsep yang membolehkan pendengar membuat andaian berdasarkan pemahaman mereka. Dengan mengambil kira keupayaan TR dalam memahami makna tersirat daripada baris sajak yang dikaji bersama-sama dengan baris-baris yang lain, kesan kognitif dalam kalangan pembaca akan menjadi lebih ketara manakala usaha untuk memproses dan memahami sajak akan menjadi rendah. Justeru, pemahaman sajak dan gambaran semangat patriotik masyarakat Cina dalam sajak yang mantap akan dapat dibina.

Dalam Jadual 1, tiga sajak karya LST serta data yang berunsur sentimen patriotik seperti dalam masyarakat Cina telah dijadikan sebagai data utama dalam kupasan ini. Baris-baris sajak yang telah dikenal pasti mengandungi semangat patriotik telah dianalisis pada tahap makna literal dan seterusnya mengikut TR.

Jadual 1. Pilihan sajak dan baris yang mengandungi nilai semangat patriotik.

\begin{tabular}{cll}
\hline Bil. data & \multicolumn{1}{c}{ Sajak } & \multicolumn{1}{c}{ Nilai semangat patriotik } \\
\hline $\mathbf{1}$ & Mari Cipta Jalan Perdamaian & Marilah cipta jalan perdamaian \\
$\mathbf{2}$ & Anakku, Inilah Tanah Air Kita & Betapa sengsara para nenek moyang yang mempertahankan \\
$\mathbf{3}$ & Warga Malaysia & Menghargai dan mengasihi tanah ini sebagai yang abadi \\
\hline
\end{tabular}

\section{ANALISIS DAN PERBINCANGAN}

Berlandaskan TR dan nilai semangat patriotik yang dibincangkan, kajian ini akan memanfaatkan beberapa baris dalam sajak-sajak kajian yang membicarakan nilai semangat patriotik dalam konteks masyarakat Cina. Selain itu, maklumat yang disumbangkan oleh baris-baris yang lain dalam menunjukkan gambaran nilai patriotisme juga akan digariskan dalam menjustifikasikan hasil analisis agar pentafsiran makna menjadi lebih tepat.

\section{Analisis TR dalam nilai semangat patriotik "Mari cipta jalan perdamaian" (Sajak "Mari Cipta Jalan Perdamaian")}

Secara harfiahnya, sajak ini mengisahkan seruan untuk mencari jalan penyelesaian yang aman dan damai terhadap cabaran yang dihadapi. Hasrat ini ditunjukkan apabila baris pertama "mari cipta jalan perdamaian" diulangi sebanyak empat kali dalam sajak untuk menyeru pembaca agar berusaha ke arah kedamaian dalam menyelesaikan masalah. Secara mudahnya, makna literal bagi baris ini ialah "perbuatan mengajak seseorang untuk berfikir tempat yang hendak dilalui untuk perihal damai. Walaupun makna literal ini mudah untuk dikesan, makna-makna ini adalah tidak memadai untuk mewakili makna yang tersirat kerana menurut Caroll (2008), makna literal ialah makna yang mendahului makna figuratif dan makna ini tidak dapat memberi penjelasan yang mendalam terhadap makna yang ingin disampaikan oleh penulis. Oleh itu, TR diperlukan untuk memberi penjelasan yang lebih lanjut dan makna sebenar sesebuah ujaran. Dalam TR, proses kod, inferens dan andaian 
telah digunakan untuk mengemas kini maklumat yang diperlukan dan data ini telah dianalisis seperti yang berikut:

\section{Analisis TR}

Baris - Mari Cipta Jalan Perdamaian

$\begin{array}{lll}\text { Kod } & \text { Inferens } & \text { Andaian } \\ \text { Jalan } & \text { Cara, kaedah, ikhtiar } & \text { 1. Tempat lalu lintas } \\ & & \text { 2. Laluan kenderaan (Jalan darat, laut, udara) } \\ & \text { 3. Pergi ke sesuatu tempat (tingkah laku) } \\ & \text { 4. Tempat yang harus dilintas atau dilalui } \\ & \text { 5. Gerakan sesuatu objek seperti enjin dan kereta } \\ & \text { 6. Perkembangan sesuatu peristiwa/ cerita } \\ & \text { 7. Cara, kaedah, ikhtiar }\end{array}$

Dalam analisis TR, pengkaji mendapati data "Mari cipta jalan perdamaian" menjadi lebih mudah difahami kerana proses pengekodan, membuat inferens dan menentukan andaian yang terdapat dalam TR telah memberi hala tuju yang lebih berfokus bagi memudahkan proses pemahaman oleh pembaca. Dengan erti kata lain, kesan kognitif akan menjadi lebih jelas berbanding dengan hanya memahami sajak dengan menggunakan makna literal. Di samping itu, melalui analisis TR, makna tersirat yang ingin disampaikan oleh penulis melalui sajak ini dapat dikaitkan dengan perihal kedamaian. Analisis TR terhadap baris ini menunjukkan sajak ini sebenarnya merujuk kepada seruan kepada seluruh warga Malaysia mengenai kepentingan kedamaian dan menyeru warga Malaysia untuk menyemai semangat ini demi negara yang tercinta. Hal ini terbukti apabila baris ini telah diulangi sebanyak tiga kali dalam sajak. Oleh hal yang demikian, dapat dijustifikasikan bahawa cara, kaedah dan ikhtiar boleh merupakan satu andaian yang menjelaskan terdapat pelbagai cara, kaedah dan ikhtiar yang boleh digunakan dalam masyarakat hari ini untuk mencapai kedamaian dan ini juga dengan jelas menyatakan bahawa kedamaian penting untuk memelihara kedaulatan sesebuah negara. Jelas andaian ini berdiri kukuh dan andaian-andaian lain didapati lemah dan digugurkan.

Tambahan pula, hasil analisis ini boleh diperkukuh melalui kaedah penggabungan dengan data "Jalan perdamaian yang mengharum kelopak rasa; Mewangi, kekal menerangi sesusur tanah tercinta". Hal ini kerana dalam TR, pendengar dibenarkan melihat kepada maklumat tambahan yang diperoleh dan dalam kajian ini, maklumat berkenaan diperoleh melalui baris-baris lain dalam sajak ini, sama ada baris yang dikemukakan dahulu atau kemudian. Maklumat ini juga dikenali sebagai ujaran sebelum dan selepas. Sebelum itu, analisis semantik terhadap baris ini telah menunjukkan perdamaian merupakan sesuatu yang penting untuk kesejahteraan sejagat. Setelah melalui analisis TR, baris ini memaparkan perkara yang berikut:

Baris - Jalan perdamaian yang mengharum kelopak rasa; Mewangi, kekal menerangi sesusur tanah tercinta

$\begin{array}{lll}\text { Kod } & \text { Inferens } & \text { Andaian } \\ \text { Menerangi } & \text { Memberi keterangan } & \text { 1. Keadaan atau kawasan yang diterangkan oleh cahaya } \\ & \text { 2. Siang hari, tidak gelap } \\ & \text { 3. Bersih, jernih, jelas, tidak kabur } \\ & \text { 4. Tidak terlindung, tiada sangsi } \\ & \text { 5. Memberi keterangan dan mencari keterangan supaya jelas }\end{array}$

Dalam analisis ini, kedua-dua data yang dianalisis telah mengemukakan konteks yang sama iaitu sebab perlunya kedamaian dan kesan positif daripada kedamaian kepada negara. Hal ini demikian kerana menurut Subet (2010), konteks merupakan seberkas andaian dunia yang dibina oleh pendengar dan ini semestinya akan membantu penginterpretasian makna kerana pendengar mampu mengaitkan konteks semasa dengan ujaran. Dengan itu, inferens daripada kedua-dua data dalam sajak ini menunjukkan keperluan untuk memikirkan cara, kaedah dan ikhtiar untuk kedamaian yang mampu memberi ketenangan kepada seluruh negara. Dengan mengambil kira keupayaan TR dalam mengupas makna tersirat daripada baris-baris sajak yang dikaji, kesan kognitif dalam kalangan pembaca akan menjadi lebih ketara dan usaha untuk memproses dan memahami sajak ini akan menjadi rendah. Bergerak daripada analisis TR yang telah dilakukan, pengkaji mendapati sajak ini adalah berkaitan rapat dengan nilai semangat patriotisme dalam masyarakat Cina yang menyatakan keperluan setiap anak bangsa untuk mengambil berat dan berusaha untuk memajukan diri demi masa depan negara. Jelas dalam sajak ini semangat patriotik dikemukakan oleh LST dalam sajak beliau ini selaras dengan nilai patriotisme yang terkandung dalam Overseas Chinese Affairs Office (2001). Maka, dalam sajak ini, jelas tergambar semangat partriotisme ini walaupun medium penulisan ialah dalam Bahasa Melayu, namun semangat patriotisme dalam kalangan masyarakat Cina ini dikemukakan oleh LST lewat sajak yang dihasilkan beliau waima bahasa yang digunakan bukan bahasa ibunda beliau. 
Hal ini demikian kerana "kedamaian" merupakan sesuatu yang perlu anak bangsa usahakan kerana setiap individu perlu memajukan diri sendiri untuk "memberi keterangan” iaitu masa depan yang baik kepada negara. Maka, dengan kedamaian, perhubungan yang erat dapat dibentuk dan ini akan memberi nafas yang baharu kepada tanah air. Dengan itu, dapat dijustifikasikan bahawa sajak ini memerihalkan nilai semangat patriotisme kerana inferens yang telah dilakukan iaitu "cara, kaedah dan ikhtiar" dan "memberi keterangan" menunjukkan kepentingan kedamaian kepada sesebuah negara. Selain itu, sajak ini turut memperlihatkan perhubungan dan perkaitan dengan nilai sentimen patriotik kerana kedamaian harus ditanam dalam jiwa raga setiap individu bagi mempertahankan tanah air daripada jajahan. Konteks yang diwujudkan dalam sajak ini daripada tajuk hinggalah ke isi kandungan telah menunjukkan perkaitan dan perhubungan daripada permulaan hingga ke pengakhiran. Ini telah mengurangkan usaha memproses maklumat dan membawa kesan kognitif yang lebih tinggi. Hal ini adalah selaras dengan pandangan Subet (2010) yang menjelaskan bahawa maklumat tambahan yang diperoleh melalui andaian-andaian ini akan menghasilkan kesan kognitif yang pelbagai dan menurut Jalaluddin (1992) pula, semakin banyak kesan kognitif terhadap sesebuah andaian, tahap kerelevanan ujaran akan bertambah dan menjadi semakin kuat.

\section{Analisis TR dalam nilai semangat patriotik "Betapa sengsara para nenek moyang yang mempertahankan" (Sajak “Anakku, Inilah Tanah Air Kita")}

Berdasarkan konteks keseluruhan sajak "Anakku, Inilah Tanah Air kita", kajian mendapati baris "betapa sengsara para nenek moyang yang mempertahankan" telah mengungkapkan pengertian bahawa nenek moyang kita telah berusaha untuk mempertahankan tanah air sewaktu penjajahan. Hal ini adalah selaras dengan catatan sejarah yang menyatakan masyarakat dahulu telah bekerjasama dengan pelbagai pihak untuk membanteras dan membantah penjajahan Jepun dan Inggeris. Maklumat perihal sejarah ini telah wujud dalam memori jangka panjang pendengar dan maklumat ini akan membantu dalam menginterpretasikan makna sebenar. Untuk baris ini, analisis pada tahap semantik telah menggambarkan usaha nenek moyang dalam melindungi tanah air. Walakin makna literal bagi baris ini begitu ringkas dan mudah diperoleh, eksplorasi terhadap baris ini dengan TR yang bertunjangkan leksikal "mempertahankan" sebagai kod analisis telah dapat mengemukakan andaian seperti berikut:

\section{Analisis TR}

Baris - Betapa sengsara nenek moyang yang mempertahankan

Kod Inferens Andaian

Mempertahankan Tidak sudi memberi atau 1. Melindungi diri sendiri, tempat

melepaskan 2. Mengekalkan sesuatu, menjaga sesuatu

3. Tidak sudi memberi atau melepaskan, tidak membiarkan pergi, tidak menganjak

4. Menyimpan sesuatu

5. Tersekat, terhambat

Dalam analisis TR, kajian mendapati makna tersirat yang ingin disampaikan melalui sajak ini berkait dengan unsur kenegaraan. Hal ini demikian kerana analisis terhadap baris ini telah menunjukkan sajak ini sebenarnya merujuk kepada sejarah Malaysia yang memperlihatkan usaha para moyang mempertahankan dan keengganan untuk melepaskan tanah air daripada belenggu pihak Jepun dan juga pihak Inggeris. Oleh hal yang demikian, keengganan dan ketidaksudian nenek moyang kita untuk menyerah tanah air boleh berupa satu andaian yang menyatakan usaha nenek moyang kita dalam melindungi tanah air dan ketidaksudian untuk menyerah kalah kepada para penjajah. Dengan itu, andaian ini akan membawa kepada konklusi bahawa setiap anak bangsa harus menyumbangkan tenaga dalam melindungi kedaulatan tanah air. Sebenarnya, pemahaman ini boleh diperoleh secara heuristik. Menurut Osman \& Jalaluddin (2018), pemahaman secara heuristik menurut TR, membolehkan pembaca untuk dapat mentafsir ujaran tersebut secara automatik tanpa memerlukan usaha memproses yang tinggi. Namun, analisis TR dilakukan sebagai pembuktian yang sahih terhadap makna yang terungkap itu sama ada itu ialah makna sebenar yang dihajati oleh penulis atau pengujar.

Sementara itu, baris yang ke-29 hinggalah ke baris yang ke -32 dalam sajak iaitu "gugur tidak berundur; atas nama perjuangan suci; demi mewariskan sesusur tanah persada; kepada kami yang hari ini kau namakan anak-anak merdeka" yang berupa maklumat tambahan juga mempunyai makna tersirat yang boleh diperdalam lagi melalui analisis TR dalam mencari makna sebenar. Hal ini kerana makna linguistik yang diperoleh iaitu "jangan mudah menyerah kalah dalam perjuangan demi tanah air" adalah tidak cukup untuk merepresentasikan makna sebenar yang tersirat. Oleh sebab yang demikian, TR diperlukan untuk mengurangkan usaha memproses dan meningkatkan kesan kognitif. Kajian ini mengesan makna sebenar yang dicari dengan TR seperti berikut: 
Baris - Gugur tidak berundur; atas nama perjuangan suci; demi mewariskan sesusur tanah persada; kepada kami yang hari ini kau namakan anak-anak merdeka

$\begin{array}{lll}\text { Kod } & \text { Inferens } & \text { Andaian } \\ \text { Gugur } & \text { Kalah } & \text { 1. Jatuh, luruh } \\ & & \text { 2. Kalah } \\ & \text { 3. Runtuh }\end{array}$

Berdasarkan analisis pada kedua-dua data yang diperoleh daripada sajak "Anakku, Inilah Tanah Air Kita”, kajian dapat mengenal pasti bahawa kedua-dua data yang diperoleh serta inferens yang dipaparkan menunjukkan perkaitan yang erat iaitu "tidak melepaskan" dan "kalah". Jikalau dimasukkan dalam konteks sajak, inferens ini dapat digabungkan menjadi "tidak melepaskan walaupun kalah". Oleh itu, inferens daripada kedua-dua data ini menunjukkan perjuangan nenek moyang kita yang berterusan untuk melindungi tanah air dengan semangat patriotisme yang tinggi walaupun menghadapi kekalahan. Dengan data yang diperoleh, kajian dapat menunjukkan proses penggabungan maklumat dalam TR dapat memudahkan interpretasi dan mendatangkan kesan kognitif yang ketara untuk memudahkan pemahaman.

Melalui analisis TR, kajian mendapati sajak ini berkait rapat dengan nilai sentimen patriotik seperti yang terkandung dalam Overseas Chinese Affairs Office (2001) kerana dalam masyarakat Cina, setiap individu harus berani berjuang dengan berhabis-habisan demi mempertahankan maruah serta kedaulatan negara. Inferens yang diperoleh dan konsep penguatan yang diaplikasikan telah menunjukkan semangat patriotik sebegini ada pada nenek moyang kita kerana mereka tidak sudi untuk melepaskan tanah air walaupun berdepan dengan kekalahan. Hal ini adalah selaras dengan pandangan Jalaluddin (2003) yang menyatakan percantuman maklumat ke atas maklumat yang baharu akan menghasilkan konteks serta kesan kognitif yang lebih menyeluruh manakala usaha memproses yang diperlukan akan menjadi kurang dan dalam TR, semakin rendah usaha memproses maka semakin tinggilah kesahan sesuatu ujaran itu.

\section{Analisis TR dalam nilai semangat patriotik "Menghargai dan mengasihi tanah ini sebagai yang abdi" (Sajak "Warga Malaysia")}

Secara harfiahnya, sajak ini mengisahkan bagaimana dan apakah yang perlu diketahui serta difahami daripada untuk menjadi seorang warga Malaysia yang baik. Berdasarkan konteks yang dibentuk dari keseluruhan sajak, kajian mendapati perihal penghargaan kepada tanah air telah disampaikan dalam sajak. Hal ini demikian kerana secara amnya, baris yang kelapan dan kesembilan "Menghargai dan mengasihi tanah ini sebagai yang abdi" membawa erti warga Malaysia haruslah menghargai dan mengasihi tanah ini yang telah diperjuangkan oleh pahlawan pada masa dahulu. Oleh sebab sajak ini memperlihatkan makna yang lebih mendalam, analisis yang berfokus haruslah dilakukan untuk menghuraikan makna sebenar dengan lebih mendalam selain daripada mengesan budaya masyarakat Cina yang tersirat. Kupasan TR bagi data ini dapat ditunjukkan dengan kod, inferens dan andaian-andaian seperti berikut:

\begin{tabular}{lll} 
& \multicolumn{1}{c}{ Analisis TR } \\
Baris & Menghargai dan mengasihi tanah ini sebagai yang abdi \\
Kod & Inferens & Andaian \\
Abdi & Menumpu seluruh jiwa dan & 1. Menjadi abdi \\
& tenaga untuk kepentingan & 2. Menumpu seluruh jiwa dan tenaga untuk kepentingan seseorang \\
& seseorang atau sesuatu & atau sesuatu \\
& 3. Perihal pengabdian
\end{tabular}

Melihat kepada analisis TR, kajian mendapati makna tersirat yang ingin disampaikan melalui sajak ini adalah berkaitan dengan aspek penghargaan dan cinta kepada negara. Hal ini demikian kerana analisis terhadap baris ini telah menunjukkan sajak ini memperlihatkan nasihat kepada para pembaca untuk menjadi seorang warganegara yang baik kepada bangsa dan negara. Oleh itu, "menumpukan seluruh jiwa dan tenaga untuk memelihara kepentingan negara" boleh merupakan satu inferens dalam menjelaskan keperluan setiap individu untuk menumpukan tenaga bagi memelihara kepentingan tanah air. Secara tidak langsung, ini akan membawa kepada konklusi bahawa setiap anak (warga) Malaysia harus menghargai dan menjaga kepentingan negara. Selain data dan interpretasi yang diperoleh, kajian turut mendapati frasa ini merupakan frasa yang bermanifestasi kerana memperlihatkan makna tersirat dan tersurat yang saling berkaitan.

Hal ini demikian kerana inferens yang diperoleh telah menunjukkan kesan kognitif dan konteks yang ketara Ini secara automatik telah mengurangkan usaha memproses yang diperlukan. Selain itu, melalui penggabungan dan 
penguatan juga, kesan kognitif dapat diwujudkan dengan lebih jelas kerana percantuman maklumat akan menghasilkan konteks serta kesan kognitif yang lebih tinggi (Jalaluddin, 2003). Justeru, tahap kerelevanan yang optimal akan dapat dicapai kerana set andaian yang dikemukakan telah memudahkan proses penginterpretasian. Berdasarkan data yang diperoleh daripada analisis TR, kajian dapat mengaitkan sajak ini dengan nilai semangat patriotisme dalam masyarakat Cina seperti yang terdapat dalam Overseas Chinese Affairs Office (2001) kerana nilai ini dalam masyarakat Cina telah membicarakan keperluan untuk menumpukan perhatian dan usaha dengan sepenuhnya untuk memakmurkan dan melindungi negara daripada ancaman luaran seperti yang diseru dalam sajak.

\section{KESIMPULAN}

Menurut TR, sesuatu ujaran yang relevans ialah ujaran yang hanya memerlukan kos memproses yang rendah tetapi kesan kognitifnya tinggi. Daripada kesan kognitif yang tinggi inilah, interpretasi sebenar sesuatu ujaran sama ada lisan atau bukan lisan diperoleh. Menerusi hasil analisis yang telah diperoleh daripada sajak-sajak yang dibincangkan, kajian ini dapat menyimpulkan bahawa penggunaan TR dalam mengenal pasti nilai sentimen patriotik dalam sajak membolehkan hasil analisis dikupas dengan lebih menyeluruh dan bukannya pada tahap permukaan sahaja. Oleh sebab hasil kesusasteraan merupakan satu wahana penyampaian yang padat dan tersirat dengan maklumat seperti sosiobudaya masyarakat, teori linguistik seperti TR haruslah diaplikasikan untuk mendapatkan makna sebenar dan mesej nilai serta pengajaran yang ingin disampaikan oleh penulis melalui penulisan mereka.

Selain itu, penganalisisan sajak ini juga menunjukkan berlakunya komunikasi silang budaya dalam mode penulisan kerana baris-baris sajak yang dikaji telah dengan jelasnya menggambarkan semangat patriotisme dalam budaya masyarakat Cina walaupuan sajak-sajak kajian dihasilkan dalam Bahasa Melayu. Dengan itu, dapat dijelaskan bahawa sastera yang dihasilkan bukan sahaja mengungkapkan pelbagai makna tersirat malahan juga terdapat gambaran aspek budaya dan pemikiran yang dipraktikkan oleh masyarakat Cina. Di samping itu, hasil analisis turut menunjukkan nilai murni masyarakat Cina yang telah disampaikan oleh nenek moyang turut dikekalkan sehingga hari ini. Hal ini dapat dijustifikasikan apabila nilai-nilai yang dipraktikkan oleh nenek moyang masyarakat Cina telah digambarkan dengan jelas dalam sajak melalui analisis TR. Jadi, dapat disimpulkan bahawa pelbagai genre hasil kesusasteraan yang telah dihasilkan oleh penulis dari pelbagai tahap dan era penulisan harus dan patut diperincikan kerana baris-baris dalam sajak menyembunyikan banyak lagi maklumat yang lebih menarik daripada makna literalnya, dengan analisis TR.

\section{PENGHARGAAN}

Setinggi-tinggi penghargaan ditujukan kepada penulis sajak iaitu Profesor Madya Dr Lim Swee Tin atas kebenaran dalam pengkajian sajak beliau.

\section{RUJUKAN}

Ahmad, A \& Jalaluddin, N. H. (2013). Implikatur dalam kes pembunuhan Noritta. Analisis teori relevans. Jurnal Bahasa, 13(1), 20-38.

Overseas Chinese Affairs Office. (2001). Common knowledge about Chinese culture. Beijing, China: Higher Education Press Ministry of Education, China.

Grice, H. P. (1975). Logic and conversation. Dalam C. Peter, \& L. M. Jerry, (Eds.), Syntax and Semantics (Vol. 3, pp. 41-58). New York, NY: Academic Press.

Jalaluddin, N. H. (1992). Semantik dan pragmatik: Satu pengenalan. Kuala Lumpur, Malaysia: Dewan Bahasa dan Pustaka.

Jalaluddin, N. H. (2003). Bahasa dalam perniagaan: Satu analisis semantik dan pragmatik. Kuala Lumpur, Malaysia: Dewan Bahasa dan Pustaka.

Jalaluddin, N. H., \& Mat Awal, N. (2006). Citra lelaki dulu dan kini dalam prosa Melayu: Analisis teori relevans. Jurnal e-Bangi, 1(1), 1-21.

Kamus Dewan (4th ed.). (2010). Kuala Lumpur, Malaysia: Dewan Bahasa dan Pustaka.

Pradopo, R. D. (1993). Pengkajian puisi: Analisis strata norma dan analisis structural dan semiotik. Yogyakarta, Indonesia: Gadjah Mada University Press.

Osman, M \& Jalaluddin, N. H. (2018). Metafora kritikan dalam mitos peminangan Puteri Gunung Ledang: Analisis Pragmatik. Jurnal Antarabangsa Dunia Melayu, 11 (1), 19-46.

Salleh, M. (2015). An introduction to modern Malaysian literature (2nd ed.). Kuala Lumpur, Malaysia: Institut Terjemahan dan Buku Malaysia.

Sperber, D. \& Wilson, D. (1986). Relevance: Communication and Cognition. Oxford, UK: Blackwell Publishing. 
Sperber, D. \& Wilson, D. (2012). Meaning and relevance. New York, NY: Cambridge University Press.

Subet, F. (2010). Interpretasi makna bahasa figuratif sebagai cerminan emosi: Satu analisis teori relevans. (Unpublished doctoral dissertation). Universiti Kebangsaan Malaysia, Bangi, Malaysia.

Subet, M. F., (2018). Analisis teori relevans dalam metafora. Jurnal Bahasa .18(1), 159-188.

Subet, M. F., \& Jalaluddin, N. H. (2014). Mengalami dan menghayati makna kemiskinan melalui Bahasa. Jurnal Bahasa, 14(1), 28-44.

\section{LAMPIRAN}

Mari cipta jalan perdamaian

Jalan perdamaian yang memadam bara permusuhan

Permusushan telah lama membakar sukma kita

Sukma kita sekian waktu ini menitis darah pedih

Kita tak mungkin lagi membiarkan pedih

Mari cipta jalan perdamaian

Jalan perdamaian yang meluntur karat kesakitan

Kesakitan telah lama mengaburi kalbu kita

Kalbu kita sekian waktu ini memutarkan ribut

keliru

Kita tak mampu lagi membiarkan keliru

Peralihan musim pantas dan lagi menguji
Kita perlu melangkah

Dengan paradigma baru lebih hakiki

Tinggalkan kepompong usang sempit tak bermakna Jenguk cakarewala luas, congak tamadun deras

Pampangkan arus gerak dalam satu derap serentak

Tanah tercinta minta dilerai rantai membelit

Belitannya telah sekian zaman menggerhanakan langit

Telah gerhana langit persaudaraan kita

Marilah cipta jalan perdamaian

Jalan perdamaian yang mengharum kelopak rasa

Mewangi, kekal menerangi sesusur tanah tercinta

Suara Kita: Antologi Seribu Sajak Merdeka (2013)
Anakku, inilah tanah air kita

500 tahun terjajah lamanya

Dari Portugis, Belanda, Inggeris, Jepun dan Inggeris kembali

Betapa sengsara para nenek moyang yang mempertahankan

Yang terkunci suara dan terantai kaki kebebasannaya

Menggeliat dalam payah, meronta dalam marah

Sebelum Ogos 31, mentari kemerdekaan membawa sinar yang cerah

Ya inilah tanah air kita

Bumi yang memberikan hati serta budaya

Kepada kami anak-anak pertiwi yang setia

Walaupun tak merasakan siat luka dan hiris derita

Kami membaca lembar demi lembar

Catatan kepahitan silan yang perlahan-lahan

Meresapkan sedar ke dasar sukma

Anakku, ini sejarah perjuangan kita

Yang telah menumoahkan darah sekalian pahlawan

Yang melahirkan ratusan malah ribuan lagi yang

bangkit menentang

Air mata bukan galang gantinya

Menjadi wargamu Malaysia adalah

WARGA MALAYSIA

Menjadi warga yang tahu pulang setelah bertandang 
Memilih kembali dan masih pandai

Menghitung bintang-bintang

Mengagum hembusan angin dan dinginnya air

Di kali peribadi

Tak janggal bersila di beranda budaya bangsa

Menghargai dan mengasihi tanah ini

Sebagai yang abdi

Inilah jalan ke negeri yang merdeka

Lemparkan keliru semerbakkan cinta

Lontarkan ragu semarakkan setia

Kebencian bukan bunga-bunga

Dendam juga bukan nyanyian

Malaysia menerimamu adalah memahatkan

kerinduan

Menjadi wargamu Malaysia adalah

Menjadi warga yang faham dan betah menghafal

Jalur sejarahmu

Kenangi kesabaran seorang Parameswara

Yang menggemilangkan sebuah kerajaan

Tak melupa detik-detik serba getir ketika kebebasan kita

Terpasung, lamanya ratusan tahun

Apa-apa sahaja atas nama harga diri tergadai

Dan duka yang terhunjam kita menatap serpihan mimpi

Para moyang yang terkecai

Jenguklah dengan percaya ke ruang rumah merdeka kita
Siapakah mencalarnya dengan petah lidah dan hujah

Mengapakah berpaling ketika ia direjam

Asakan rentapnya lain

Apakah isi suratmu tatkala negara digelumangi duga

Tingkap malammu benarkah kaubuka untuk rama-rama

Aku hanya memilih sekujur ini dalam sengsara walau

Dan sejahteranya juga

Menjadi wargamu malaysia adalah

Menjadi warga yang pantas mentafsir pedaya serta helah

Terkilas sisik asing terpancar makna yang dikirim

Belajarlah bagaimana tak mudah dipukau

Metafora mencurah

Pahit keringitan dan hangat darah di monumen seakan

Baharu sahaja tumpah

Kita masih di hutan perjuangan jaraknya sejauh

Ikrar dan sumpah

Menjadi wargamu Malaysia adalah

Menjadi warga yang kenal sempadan kemerdekaannya

Sajak-sajak Sempena Citra Kurnia (2003) 